\title{
Prevalence of Intestinal Parasites in HIV Seropositive Patients with and without Diarrhoea and its Correlation with CD4 Counts
}

\author{
S. Sreedevi ${ }^{*}$, V. Aarthi ${ }^{2}$ and K. Saraswathi ${ }^{1}$ \\ ${ }^{1}$ Department of Microbiology, Santhiram Medical College, Nandyal, A.P, India \\ ${ }^{2}$ Department of Microbiology, Kurnool Medical College, Kurnool, AP, India \\ *Corresponding author
}

\section{Keywords}

Intestinal Parasites, HIV Seropositive Patients, Diarrhoea and its Correlation.

\section{Article Info}

Accepted: 18 September 2016 Available Online: 10 October 2016

\section{A B S T R A C T}

Intestinal parasites are the most common cause of diarrhoea in HIV patients. The line of treatment being different for diverse parasites necessitates a definitive diagnosis of etiological agents. Thus the study was undertaken to detect enteric parasites in HIV infected patient with and without diarrhoea that were at different levels of immunity. The present study was conducted in between January 2013 June 2014, at the Department of Microbiology, Santhiram General Hospital, Nandyal. A total of $100 \mathrm{HIV}$ seropositive patients attending the Integrated Counselling and Testing Centre (ICTC), Santhiram General Hospital, Nandyal, Kurnool Dist, A.P was included in the study. These comprised of 50 HIV patients who presented with diarrhoea (study group) and 50 HIV patients without diarrhoea (control group). For each patient, demographic data including structured questionnaire was filled in the proforma. The CD4 cell counts were estimated by using the FACS count system. Out of 100 HIV infected patients, intestinal parasites were detected in $29 \%$ patients. Among all, Cryptosporidium appears to have the high prevalence (26\%) followed by Isospora (10\%), Giardia (6\%), Strongyloides and Entamoeba histolytica (4\%) each and Cyclospora (2\%). In HIV infected patients with CD4 count $<200$ cells/ml. Cryptosporidium was the most common observed pathogen $(26 \%)$. The maximum parasite isolation was in the patients whose CD 4 cell counts were below 200 cells/ml. Parasitic infections were detected in $29 \%$ of HIV seropositive patients and various enteric parasites detected include Cryptosporidium (15), Isospora (05), Giardia intestinalis (04), Entamoeba histolytic (02) Cyclospora (01), Strongyloides (02).Routine screening of all HIV infected patients with low CD4 count for parasitic infections by using simple stool microscopic technique can help in easy diagnosis of approximate treatment and control of spread.

\section{Introduction}

Human immunodeficiency virus infection has become a global epidemic far extensive than what was predicted even a decade ago and the pace of the epidemic is accelerating in India (Anand et al., 2013). Since the beginning of the epidemic, estimates suggest 
that more than 60 million people have become infected and more than 20 million people have died of HIV/AIDS, including 3 million deaths in 2001 alone of the global total number of people who are living with HIV, 95\% live in developing countries. India, where 3.97 million Indians are living with HIV/AIDS, has the highest number of HIV infected persons in Asia (Anuradha, 2013).

In the coming years there is likely to be an increase in the number of HIV/Aids deaths, with worrying projections of 6.5 million deaths in 2030 and HIV/AIDS being the main burden of disease in some developing countries by 2015 (Arora et al., 2009).

In HIV infected patients, progressive decline in their immunological response makes them extremely susceptible to a variety of opportunistic infections. Opportunistic infections (O.I's) have been recognised as common complications of HIV infection. The spectrum of O.I's in the HIV infected patients varies from one region to another. Gastro intestinal infections are very common in patients with AIDS which presents commonly in diarrhea (Arora et al., 2006). Reports indicate that diarrhea occurs in $30-60 \%$ of AIDS patients in developed countries and in about $90 \%$ of AIDS patients in Haiti and Africa (Gupta, 2008).

Enteric protozoal infection is the commonest cause of diarrhea in HIV seropositive persons. Diarrhea was defined as passage of two or more liquid stools or three or more soft stools per day (Kumar, 2002). Diarrhoea associated with HIV infection may be acute or chronic. Acute diarrhoea is defined as diarrhoea of $<14$ days duration and chronic diarrhoea is defined as diarrhoea lasting for $>14$ days to four months or diarrhoea for more than a month. Diarrhoea occurs in almost $90 \%$ of patients with HIV in developing countries at sometime during the clinical course and is the present symptom of approximately a third of patients with HIV infection (Kumarasamy et al., 2005). Chronic diarrhoea is a major problem in HIV infected persons, affecting upto $76 \%$ of those with AIDS. It is associated with a 3.3 fold increase risk of disease progression. Chronic diarrhea significantly reduces the quality of life in patients with HIV infection and is an independent predictor of mortality in AIDS (Kumarasamy et al., 2005).

The common parasites causing AIDS associated with and without diarrhoea are (Mohandas et al., 2002)

\section{Cryptosporidium parvum}

Isospora belli

Cyclospora cayetanensis

Microsporidia

Strongyloides stercoralis

Entamoeba histolytica

\section{Giardia lamblia}

The outcome of the infection by enteric protozoan parasites is dependent on absolute CD4+ counts, with lower counts being associated with more severe disease and a greater risk of disseminated disease. CD4 counts of $<100$ cells/ $\mu 1$ poses greatest risk.

\section{Materials and Methods}

The study was conducted between January 2013 - June 2014, at the Dept of Microbiology, Santhiram Medical College, Nandyal.

The purpose of the study is to determine the prevalence of intestinal parasites and their association with diarrhoea in HIV infected patients. And to elucidate the association between intestinal parasitic infection and CD4 counts in HIV infected patients. 
A total of 100 HIV seropositive patients attending the Integrated Counselling and Testing Centre (ICTC), Santhiram General Hospital, Nandyal, Kurnool Dist, A.P were included in the study. These comprised of 50 HIV patients who presented with diarrhoea (study group) and 50 HIV patients without diarrhoea (control group).

HIV infected patients were defined as those who had tested positive for HIV antibodies by three sequential rapid tests as per the recommendations given by the National AIDS Control Organization (NACO). All the tests were done after due patient consent and in accordance with the instituitional ethical guidelines.

For each patient, demographic data including a structured questionnaire was filled in the proforma.

\section{Study group}

\section{Inclusion criteria}

HIV seropositive patients with acute or chronic diarrhoea and

HIV seropositive patients who did not receive antiparasitic treatment for diarrhoea were included in the study

\section{Exclusion criteria}

HIV seropositive patients who received antiparasitic treatment for diarrhoea in the past 14 days were excluded.

\section{Parasitological examinations}

Stool samples were collected in a wide mouthed, leakproof, clean, dry, plastic containers. The patients were instructed to avoid contamination of stool with urine or water. Fresh stool samples were collected from each subject and were examined for parasites as per the standard laboratory procedures immediately. If there was a delay in processing the samples, they were preserved at $4 \mathrm{C}$. A small portion of sample was emulsified in a drop of saline and Lugol's iodine on the slide and observed under microscope. The samples were concentrated by formol ether sedimentation and Sheather's sugar floatation technique. Thereafter the samples were stained by Modified acid fast technique, Auramine-O staining technique for C.parvum, I.belli, Cyclospora and Modified Trichrome stain for Microsporidia.

\section{Results and Discussion}

A total of 100 stool samples from HIV seropositive patients were examined for the enteric parasitic infection. Out of $100 \mathrm{HIV}$ infected patients, $58(58 \%)$ were male patients and $42(42 \%)$ were female patients. The majority of HIV infected patients belonged to $31-40$ year age group in males and 20 - 30 year age group in females. Intestinal parasites were detected in all the age groups and in both the sexes.

Cryptosporidium was the most common parasite detected in $13 / 50(26 \%)$ patients with diarrhoea. Isospora was next commonly isolated parasite 5/50 (10\%).

Majority of the parasites were detected in patients with CD4 counts $<200$ cells $/ \mathrm{ml}$. Out of 21 stool samples positive for coccidian parasites, all 21 were detected by Sheather's sugar floatation method and only 17 were detected by Formol-ether concentration method.

In the present study, a total of $100 \mathrm{HIV}$ seropositive patients were studied. Majority of the patients $(36 \%)$ belonged to age group 31-40 years. Similar age group studies have been reported in HIV seropositive patients 
by others (Vyas et al., 2012; Uppal et al., 2009).

In the present study, intestinal parasites were detected in 58\% of HIV infected patients with diarrhoea and without diarrhoea. This study corroborates well with other studies which reported a prevalence of intestinal parasites ranging from $30 \%$ to $60 \%$ in HIV infected patients (Mukhopadhya et al., 1999; Vyas et al., 2012).

In the present study, coccidian parasites were detected in $73.14 \%$ of stool samples of HIV infected patients. Other studies reported a prevalence rate of $76.3 \%$ (Gupta et al., 2008)

In the present study, Cryptosporidium was found to be predominant $(26 \%)$ intestinal parasite associated with diarrhoea which is in accordance with other studies (Basak et al., 2010; Mohan Das et al., 2002) and the association of Cryptosporidium with and without diarrhoea in HIV infected patients is highly significant $(p=0.000$ i.e $<0.01)$.

Isospora was detected in 18\% (9 out of 50) of HIV positive diarrhoea patients, slightly lower detection rates as compared to earlier studies may be due to intermittent shedding of oocysts.

In the present study, Cyclospora was detected from stools of $2 \%$ (1/50) HIV positive diarrhoea patients. Cyclospora was detected in $0.98 \%$ and $4.9 \%$ of HIV positive diarrhoea patients in previous studies done in Southern India (Kumar et al., 2002; Gupta et al., 2008).

Table.1 Distribution of age and sex among $100 \mathrm{HIV}$ infected patients

\begin{tabular}{|l|l|l|}
\hline Age (years) & $\begin{array}{l}\text { Males } \\
\mathbf{n = 5 8}\end{array}$ & $\begin{array}{l}\text { Females } \\
\mathbf{n = 4 2}\end{array}$ \\
\hline $20-30$ & 10 & 24 \\
\hline $31-40$ & 24 & 12 \\
\hline $41-50$ & 14 & 5 \\
\hline $51-60$ & 8 & 1 \\
\hline $61-70$ & 2 & - \\
\hline
\end{tabular}

Table.2 Enteric parasites detected from HIV infected patients with and without diarrhea

\begin{tabular}{|l|l|l|}
\hline Parasites & $\begin{array}{l}\text { No.of parasites in } \\
\text { patients with } \\
\text { diarrhoea } \\
\mathbf{n = 5 0}\end{array}$ & $\begin{array}{l}\text { No.of parasites in } \\
\text { patients without } \\
\text { diarrhoea } \\
\mathbf{n = 5 0}\end{array}$ \\
\hline Cryptosporidium & 13 & 2 \\
\hline Isospora belli & 5 & - \\
\hline Giardia lamblia & 3 & 1 \\
\hline Entamoeba histolytica & 1 & 1 \\
\hline Cyclospora cayetanensis & 1 & - \\
\hline Strongyloides & 2 & - \\
\hline
\end{tabular}


Table.3 Comparative results of Formol-ether concentration method and Sheather's sugar floatation method for coccidian parasites

\begin{tabular}{|c|c|c|}
\hline $\begin{array}{l}\text { Total no.of stool samples } \\
\text { positive for parasites }\end{array}$ & $\begin{array}{l}\text { No.of positives by Formol- } \\
\text { ether } \\
\text { method }\end{array}$ & $\begin{array}{l}\text { No.of positives by } \\
\text { Sheather's } \\
\text { floatation method }\end{array}$
\end{tabular}

Table.4 Associaion between parasites isolated and CD4 counts of HIV infected patients

\begin{tabular}{|c|c|c|c|}
\hline Parasites & $\begin{array}{l}\text { CD4counts }<200 \\
\text { cells/ } \mu \mathrm{l}\end{array}$ & $\begin{array}{l}\text { CD4 counts } 200- \\
500 \text { cells/ } \mu \mathrm{l}\end{array}$ & $\begin{array}{l}\text { CD4 counts }>500 \\
\text { cells/ } / \mu 1\end{array}$ \\
\hline Cryptosporidium & 10 & 3 & 2 \\
\hline Isospora belli & 5 & & \\
\hline Giardia lamblia & 2 & 1 & 1 \\
\hline Entamoeba histolytica & 1 & 1 & \\
\hline $\begin{array}{l}\text { Cyclospora } \\
\text { cayetanensis }\end{array}$ & 1 & - & - \\
\hline Strongyloides & 2 & & \\
\hline Total & 21 & 5 & 3 \\
\hline
\end{tabular}

Microsporidia was not detected in the present study similar to a few other studies because of striking geographical variations in the prevalence of the parasite in HIV infected patients.

Giardia lamblia and Entamoeba histolytica were the common non-coccidian protozoan parasites demonstrated in the stool of HIV infected patients. Detection of Giardia (4\%) and Entamoeba histolytica (2\%) in the present study is consistent with the findings of other authors (Talib and Singh, 1998; Mukhopadhya et al., 1999).

It is concluded from the present study that Cryptosporidium is the commonest intestinal protozoan parasite in HIV infected patients with diarrhoea. Hence it is necessary that HIV/AIDS patients presenting with diarrhoea should be screened for enteric parasites with most accurate staining methods. Based on the present study we conclude that special staining methods like
Modified Z-N method and concentration methods like Sheather's sugar floatation method should be employed as a part of routine testing for detection of intestinal parasites in HIV infected patients. This will guide clinicians to start an early and appropriate treatment and thus improve the quality of life of such patients. Routine screening of all the HIV infected patients with low CD4 counts for coccidian parasites by using simple stool microscopic techniques can help in early diagnosis, initiation of appropriate treatment and control of spread.

\section{References}

Anand, B., Janagond, et al. 2013. Enteric Parasitic Infections in Relation to Diarrhoea in HIV Infected Individuals with CD4 T Cell Counts < 1000 cells $/ \mu 1$ in Chennai, India. J. Clin. Diag. Res., 7(10): 2160-2162. 
Anuradha De. 2013. Current Laboratory Diagnosis of Opportunistic Enteric Parasites in Human Immunodeficiency Virus-infected Patients. Trop. Parasitol., 3(1) : 7-16.

Arora, D.R. et al. 2003. HIV - 1 Therapeutic Vaccine : A Ray of Hope. Indian J. Med. Microbiol., 21(4): 225232.

Arora, et al. 2009. AIDS- associated parasitic diarrhoea. Indian J. Med. Microbiol., 27(3): 185-190.

Basak, S., Bose, S., Mallick, S.K., Ghosh, A.K. 2010. Intestinal parasitic infections in HIV seropositive patients - A study. J. Clin. Diag. Res., 4: 2433-2437.

Gupta, S., Narang, S., Nunavath, V., Singh, S. 2008. Chronic diarrhoea in HIV patients: prevalence of coccidian parasites. Indian J. Med. Microbiol., 26(2) : 172-175.

Kulkarni, S.V. et al. 2009. Opportunistic Parasitic Infections in HIV/AIDS Patients Presenting with diarrhoea by the Level of Immunesuppression. Indian J. Med. Res., 130: 63-66.

Kumar, S.S. et al. 2002. Intestinal Parasitic Infection in HIV infected Patients with diarrhoea in Chennai. Indian J. Med. Microbiol., 20(2) : 88-91.

Kumarasamy, N. et al. 2005. Clinical profile of HIV in India. Indian J. Med. Res., 121: 377-394.
Kumaraswamy, N. et al. 2003. Natural History of Human Immunodeficiency Virus Disease in Southern India. Clin. Infect. Dis., 36: $79-85$.

Mohandas Kava, et al. 2002. Prevalence of Intestinal Parasitic Pathogens in HIV seropositive individuals in Northern India. Japanese J. Infect. Dis., 55: 8384.

Mukhopadhya Ashis, et al. 1999. Enteric pathogens in Southern Indian HIV infected patients with and without diarrhoea. Indian J. Med. Res., 109: 85-89.

Parija, S.C. 2010. Text book of Medical Parasitology: $3^{\text {rd }}$ ed. New Delhi: All India Publishers and Distributors.

Sharpstone, D., B. Gazzard. 1996. Gastrointestinal Manifestations of HIV infection. Lancet, 348: 379-383.

Talib, S.H., Singh, J. 1998. A study on opportunistic enteric parasites in 80 HIV seropositive patients. Indian $J$. Pathol. Microbiol., 41: 31-37.

Uppal, et al. 2009. Enteric pathogens in HIV/AIDS from a tertiary care hospital. Indian J. Community Med., 34(3): 237-242.

Vyas, N. et al. 2012. Enteric pathogens in HIV-positive Patients with diarrhoea and Their Correlation with CD4+ Tlymphocyte counts. Tropical Parasitol., 2(1): 29-34.

\section{How to cite this article:}

Sreedevi, S., V. Aarthi and Saraswathi, K. 2016. Prevalence of Intestinal Parasites in HIV Seropositive Patients with and without Diarrhoea and its Correlation with CD4 Counts. Int.J.Curr.Microbiol.App.Sci. 5(10): 527-532. doi: http://dx.doi.org/10.20546/ijcmas.2016.510.058 